\title{
Phonon-boundary scattering and thermal transport in AlxGa1-xN: Effect of layer thickness
}

Dat Tran, Rosalia Delgado Carrascon, John F. Muth, Tania Paskova, Muhammad Nawaz, Vanya Darakchieva and Plamen Paskov

The self-archived postprint version of this journal article is available at Linköping University Institutional Repository (DiVA):

http://urn.kb.se/resolve?urn=urn:nbn:se:liu:diva-172917

N.B.: When citing this work, cite the original publication.

Tran, D., Delgado Carrascon, R., Muth, J. F., Paskova, T., Nawaz, M., Darakchieva, V., Paskov, P., (2020), Phonon-boundary scattering and thermal transport in AlxGa1-xN: Effect of layer thickness, Applied Physics Letters, 117(25), 252102. https://doi.org/10.1063/5.0031404

Original publication available at:

https://doi.org/10.1063/5.0031404

Copyright: American Institute of Physics

http://www.aip.org/ 


\title{
Phonon-boundary scattering and thermal transport in $\mathrm{Al}_{x} \mathrm{Ga}_{1-x} \mathrm{~N}$ : Effect of layer thickness
}

\author{
Dat Q. Tran, ${ }^{1,2, \text { a) }}$ Rosalia Delgado-Carrascon,,${ }^{1,2}$ John F. Muth, ${ }^{3}$ Tania Paskova, ${ }^{3}$ Muhammad Nawaz, ${ }^{2,4}$ Vanya \\ Darakchieva, ${ }^{1,2,5}$ and Plamen P. Paskov ${ }^{1,2,3}$ \\ 1) Department of Physics, chemistry, Biology, Linköping University, 58183 Linköping, \\ Sweden \\ ${ }^{2)}$ Center for III-Nitride Technology, C3NiT-Janzen, Linköping University, 58183 Linköping, \\ Sweden \\ 3) Department of Electrical and Computer Engineering, NCSU, Raleigh, NC 27695, USA \\ ${ }^{4)}$ Hitachi ABB Power Grids, Power Grid Research, Forskargränd 7, 72178 Västerås, \\ Sweden \\ ${ }^{5)} \mathrm{THz}$ MAterials Analysis Center (TheMAC), Linköping University, 58183 Linköping, \\ Sweden
}

(Dated: 25 February 2021)

Thermal conductivity of $\mathrm{Al}_{x} \mathrm{Ga}_{1-x} \mathrm{~N}$ layers with $0 \leq x \leq 0.96$ and variable thicknesses are systematically studied by combined thermoreflectance measurements and a modified Callaway's model. We find a reduction in the thermal conductivity of $\mathrm{Al}_{x} \mathrm{Ga}_{1-x} \mathrm{~N}$ by more than one order of magnitude compared to $\mathrm{GaN}$ indicating a strong effect of the phonon-alloy scattering. It is shown that the short-mean-free-path phonons are strongly scattered, which leads to a major contribution of the long-mean-free-path phonons to the thermal conductivity. In thin layers, the long-mean-freepath phonons become efficiently scattered by the boundaries resulting in a further decrease of the thermal conductivity. Also, an asymmetry of thermal conductivity as a function of Al content is experimentally observed and attributed to the mass difference between $\mathrm{Ga}$ and $\mathrm{Al}$ host atoms.

Ultra-wide bandgap semiconductors (UWBS) with gaps wider than the $3.4 \mathrm{eV}$ of $\mathrm{GaN}$ have emerged as promising materials for next generation high power electronics. ${ }^{1}$ Many of the important factors for power device performance, such as the critical electric field for avalanche breakdown $\left(E_{c}\right)$, increase nonlinearly with the bandgap energy $\left(E_{g}\right)$, e.g., $E_{c}$ $\sim\left(\mathrm{E}_{g}\right)^{n}$, where $n=2 \div 2.5 .^{2}$ Among the numerous UWBS explored so far for power electronics, $\mathrm{Al}_{x} \mathrm{Ga}_{1-x} \mathrm{~N}$ ternary alloys represent particular interest due their bandgap tunability from $3.4 \mathrm{eV}$ to $6 \mathrm{eV}$. The latter enables critical electric field of up to $16 \mathrm{MV} / \mathrm{cm}$ in $\mathrm{Al}_{x} \mathrm{Ga}_{1-x} \mathrm{~N}$, significantly exceeding those of any semiconductor currently employed in commercial power electronic devices. In addition, $\mathrm{Al}_{x} \mathrm{Ga}_{1-x} \mathrm{~N}$ can be both $n$ - and $p$-type doped ${ }^{3-6}$ permitting variety of device designs with reduced energy loss during operation.

Recently, $\mathrm{Al}_{x} \mathrm{Ga}_{1-x} \mathrm{~N}$ have been employed as channel layers in high electron mobility field effect transistors (HEMTs) with remarkable improvement in breakdown voltage and the stabilization of saturation current against temperature. ${ }^{7-10}$ Quasi-vertical $\mathrm{Al}_{x} \mathrm{Ga}_{1-x} \mathrm{~N}$ devices such as $1600 \mathrm{~V} \mathrm{Al}_{0.3} \mathrm{Ga}_{0.7} \mathrm{~N} p-i-n$ diode ${ }^{11}$ and $\mathrm{Al}_{0.3} \mathrm{Ga}_{0.7}$ Schottky diode with breakdown voltage of $500 \mathrm{~V}^{12}$ have also been demonstrated.

Thermal conductivity is a key material parameter for power electronic device design and optimization as it determines the efficiency with which generated heat can be removed. Reports on thermal conductivity of $\mathrm{Al}_{x} \mathrm{Ga}_{1-x} \mathrm{~N}$ are scarce and only limited information for $\mathrm{Al}$ molar fraction below 0.44 exists. ${ }^{13-16}$ In addition, nothing is known about the effect of layer thickness and phonon-boundary scattering in

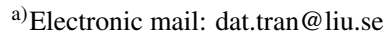

$\mathrm{Al}_{x} \mathrm{Ga}_{1-x} \mathrm{~N}$. The latter have been shown to play a critical role for $\mathrm{GaN}$, where significant reduction of thermal conductivity with decreasing film thickness was observed. ${ }^{17,18}$ We note that $\mathrm{Al}_{x} \mathrm{Ga}_{1-x} \mathrm{~N}$ layers with variable thicknesses are needed for optimizing thermal resistance across HEMT, Schottky diode, and $p-i$ - $n$ diode structures for power devices.

In this work, we present a systematic study of the thermal conductivity of $\mathrm{Al}_{x} \mathrm{Ga}_{1-x} \mathrm{~N}$ with $\mathrm{Al}$ content $0 \leq x \leq 0.96$ with variable thicknesses. We determine the effect of thickness on the thermal transport in $\mathrm{Al}_{x} \mathrm{Ga}_{1-x} \mathrm{~N}$ layers and discuss the interplay of the phonon-boundary and phonon-alloy scattering mechanisms.

Single-crystalline (0001) $\mathrm{Al}_{x} \mathrm{Ga}_{1-x} \mathrm{~N}$ layers were grown on $c$-plane GaN bulk or $c$-plane sapphire substrates by Halide Vapor Phase Epitaxy (HVPE) at Kyma Technologies, Inc. Layers with $\mathrm{Al}$ content of $0.13 \leq x \leq 0.96$ and thicknesses in the range of $0.7-24 \mu \mathrm{m}$ were investigated. In addition, $\mathrm{GaN}$ layers grown on $4 \mathrm{H}-\mathrm{SiC}$ by hot-wall netalorganic chemical vapor deposition (MOCVD) using 50-nm-thick AIN nucleation layers were also studied. Details about the samples are listed in Table 1. The Al content and dislocation densities were determined by high-resolution X-ray diffraction (HRXRD) measurements, the layer thickness was obtained by UV-VIS ellipsometry and reflectance spectroscopy.

Thermal conductivity measurements were performed by transient thermoreflectance (TTR). The system we have used comprises a pump laser (a pulse double-frequency Nd:YAG laser emitting at $532 \mathrm{~nm}$ with $8 \mathrm{~ns}$ pulse duration and a repetition rate of $50 \mathrm{~Hz}$ ) and a probe laser (a continuous-wave $\mathrm{Ar}$ laser emitting at $488 \mathrm{~nm}) .{ }^{19}$ The pump laser heats the sample through a $200 \mathrm{~nm}$ thick Au transducer deposited on the top sample surface. The decay of the sample temperature after pump laser pulse is monitored by measuring of the reflectance of the probe laser. The spot size of the probe laser is cho- 
TABLE I. Al content, layer thickness $(\mathrm{L})$, screw $\left(\mathrm{D}_{S}\right)$ and edge $\left(\mathrm{D}_{E}\right)$ dislocation densities, and thermal conductivity, $\mathrm{k}$, measured at $300 \mathrm{~K}$ of the samples under investigation.

\begin{tabular}{|c|c|c|c|c|c|c|}
\hline \multicolumn{2}{|l|}{ samples } & $\mathrm{Al}$ content $(\%)$ & $\mathrm{L}(\mu \mathrm{m})$ & $\mathrm{D}_{S}\left(\mathrm{~cm}^{-2}\right)$ & $\mathrm{D}_{E}\left(\mathrm{~cm}^{-2}\right)$ & $\mathrm{k}$ at $300 \mathrm{~K}(\mathrm{~W} / \mathrm{m} . \mathrm{K})$ \\
\hline \multirow{3}{*}{ GaN } & G1 & 0 & 1.0 & $2 \times 10^{7}$ & $9 \times 10^{7}$ & 115 \\
\hline & $\mathrm{G} 2$ & 0 & 1.6 & $4 \times 10^{7}$ & $2 \times 10^{8}$ & 138 \\
\hline & G3 & 0 & 2.1 & $2 \times 10^{7}$ & $8 \times 10^{7}$ & 157 \\
\hline \multirow{7}{*}{$\mathrm{AlGaN}$ on $\mathrm{GaN}$} & A1 & 13 & 0.7 & $9 \times 10^{8}$ & $9 \times 10^{9}$ & 9.4 \\
\hline & A2 & 16 & 12 & $2 \times 10^{9}$ & $8 \times 10^{9}$ & 16 \\
\hline & A3 & 16 & 22 & $8 \times 10^{8}$ & $1 \times 10^{10}$ & 16 \\
\hline & A4 & 26 & 0.7 & $4 \times 10^{9}$ & $3 \times 10^{10}$ & 7.1 \\
\hline & A5 & 30 & 12 & $2 \times 10^{9}$ & $1 \times 10^{10}$ & 11 \\
\hline & A6 & 30 & 24 & $9 \times 10^{8}$ & $8 \times 10^{9}$ & 12 \\
\hline & A7 & 96 & 1.3 & $5 \times 10^{8}$ & $1 \times 10^{10}$ & 22.5 \\
\hline \multirow{6}{*}{$\mathrm{AlGaN}$ on sapphire } & B1 & 43 & 3.1 & $4 \times 10^{9}$ & $6 \times 10^{9}$ & 9.9 \\
\hline & B2 & 56 & 1.4 & $5 \times 10^{9}$ & $1 \times 10^{10}$ & 7.4 \\
\hline & B3 & 60 & 6.6 & $5 \times 10^{9}$ & $1 \times 10^{10}$ & 9.1 \\
\hline & B4 & 82 & 8.2 & $5 \times 10^{9}$ & $1 \times 10^{10}$ & 9.4 \\
\hline & B5 & 88 & 1.4 & $8 \times 10^{8}$ & $6 \times 10^{9}$ & 10.2 \\
\hline & B6 & 89 & 5.6 & $8 \times 10^{8}$ & $2 \times 10^{10}$ & 13.2 \\
\hline
\end{tabular}

sen to be much smaller than that of the pump laser ensuring that the heat transport along the direction perpendicular to the sample surface is probed in the experiment. Therefore, in our measurements we determine the out-of-plane thermal conductivity along the $c$-axis. The thermal conductivity was obtained via a least-square fit of the reflectance transients of the probe laser with the solution of one-dimensional heat transport equation. In the fitting procedure, two fitting parameters were used - the layer thermal conductivity and the thermal resistance at the Au/layer or layer/substrate. The thermal conductivity of bare substrates ( $\mathrm{GaN}$ and sapphire) was initially measured and used as an input for the analysis.

The experimental thermal conductivity data in this work was analysed in the framework of modified Callaway's model, where the individual scattering contributions of longitudinal and transverse acoustic phonons are taken into account. ${ }^{20-23}$ The contribution of the optical phonons is expected to have a minor effect on the thermal conductivity of III-nitride semiconductors due to $i$ ) the large energy gap between the acoustic and optical phonons and $i$ ) the flat dispersion of the optical phonons. ${ }^{24,25}$ In modified Callaway's model, the thermal conductivity is given by ${ }^{22,23}$

$k=\sum_{s} \frac{k_{B}^{4}}{6 \pi^{2} \hbar^{3} v_{s}} T^{3}\left(\int_{0}^{\theta_{D}^{s} / T} \tau_{C}^{s} f(y) d y+\frac{\left[\int_{0}^{\theta_{D}^{s} / T} \frac{\tau_{C}^{s}}{\tau_{N}^{s}} f(y) d y\right]^{2}}{\left[\int_{0}^{\theta_{D}^{s} / T} \frac{\tau_{C}^{s}}{\tau_{N}^{s} \tau_{R}^{s}} f(y) d y\right]}\right)$

where $k_{B}$ is the Boltzmann constant, $T$ is the temperature, $\hbar$ is the reduced Planck constant, $v_{s}$ is the acoustic phonon velocity, and and $\theta_{D}^{s}$ is the Debye temperature. An integral variable $x=\hbar \omega / k_{B} T$ is used instead of the phonon frequency $\omega$, and $f(y)=y^{4} \exp (y) /[\exp (y)-1]^{2}$. The summation is over the three acoustic modes - one longitudinal and two transverse, i. e. $s=\mathrm{LA}, \mathrm{TA} 1, \mathrm{TA} 2$. Note that for a phonon propagation along the $c$-axis of wurtzite crystals, the two transverse modes are degenerated. The phonon velocities are calculated by $v_{T A 1}=v_{T A 2}=\left(C_{44} / \rho\right)^{1 / 2}$ and $v_{L A}=\left(C_{33} / \rho\right)^{1 / 2}$, where $C_{i j}$ are the elastic constants and $\rho$ is the density. The Debye temperature is determined from the zone boundary frequency at A symmetry point of the Brillouin zone $\omega_{\max }$ by $\theta_{D}=\hbar \omega_{\max } / k_{B}$. In Eq. (1) $\tau_{N}^{s}$ denotes the relaxation time for normal $(N)$ phonon scattering, $\tau_{R}^{s}$ is the relaxation time taken to be additive of all resistive $(R)$ scattering processes, and $\tau_{C}^{s}$ is the combined relaxation time given by $\left(\tau_{C}^{s}\right)^{-1}=\left(\tau_{N}^{s}\right)^{-1}+\left(\tau_{R}^{s}\right)^{-1}$. The resistive scattering processes included in our analysis are Umklapp $(U)$ phonon-phonon scattering, the phonon-isotope $(I)$ scattering, the phonondislocation $(D)$ scattering, the phonon-alloy $(A)$ scattering and the phonon-boundary $(B)$ scattering. The phonon-pointdefect $(P D)$ scattering is excluded because all samples studied are undoped with a residual impurity concentration below $10^{17} \mathrm{~cm}^{-3}$. Then, Matthiessen's rule is applied for $\tau_{R}^{s}$, i. e. $\left(\tau_{R}^{s}\right)^{-1}=\left(\tau_{U}^{s}\right)^{-1}+\left(\tau_{I}^{s}\right)^{-1}+\left(\tau_{D}^{S}\right)^{-1}+\left(\tau_{A}^{s}\right)^{-1}+\left(\tau_{B}^{s}\right)^{-1}$.

The $N-, U-, I-$, and $D$-scattering processes are treated using the scattering rate expressions proven to described rather well the experimental thermal conductivity data of $\mathrm{GaN}^{23,26,27}$ For $D$-scattering Paskov et al. ${ }^{27}$ have introduced a correction factor of $10^{3}$ in the commonly used $D$-scattering rate expression $^{26}$ in order to match the threshold value of the threading dislocation density on the thermal conductivity experimentally found in thick HVPE GaN layers. ${ }^{28}$ Based on the recent thermal conductivity measurements in $\mathrm{GaN}$ layers with varying dislocation density ${ }^{29,30}$ this correction factor was refined, and a value of $4 \times 10^{2}$ was used in this work.

The $A$-scattering is described in the framework of the virtual crystal approximation,in which the disordered alloy is replaced by an ordered virtual crystal with virtual atomic mass, atomic volume and lattice constants. ${ }^{15,31,32}$ Then, the acoustic phonons are scattered by the perturbations of the virtual crystal. The expression for $A$-scattering rate is similar to that for the $P D$-scattering rate ${ }^{33}$, but modified to take into account the coexistence of the substitutional $\mathrm{Al}$ into $\mathrm{GaN}$ lattice and 

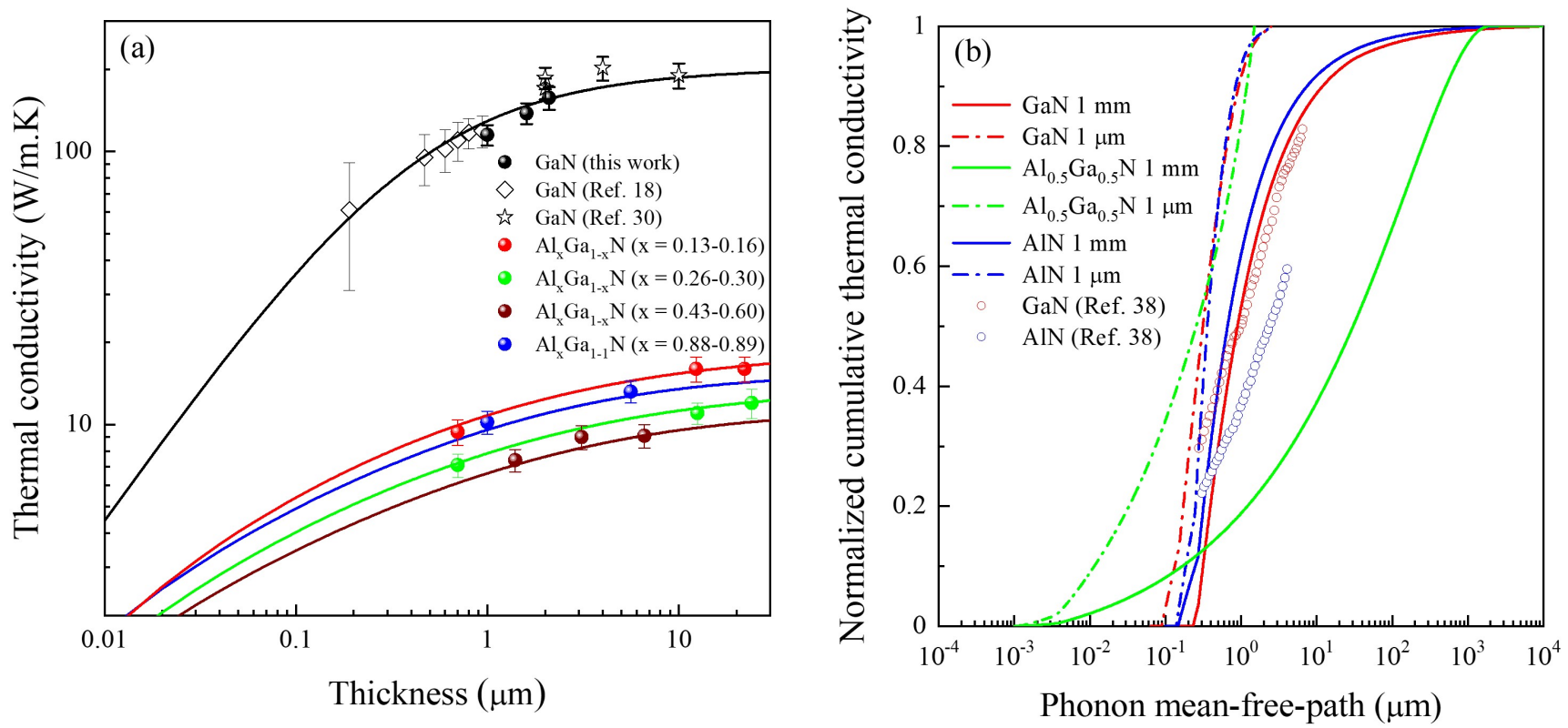

FIG. 1. (a) Thickness dependence of the thermal conductivity of $\mathrm{GaN}$ and $\mathrm{Al}_{x} \mathrm{Ga}_{1-x} \mathrm{~N}$. Data for GaN from Refs. 18 and 30 are indicated with open symbols. The curves represent the fit to all data using the modified Callaway's model with $a$ in Eq. (4) as an adjustable parameter. (b) Normalized cumulative thermal conductivity as a function of phonon MFP calculated for $\mathrm{GaN}$, $\mathrm{AlN}$, and $\mathrm{Al}_{0.5} \mathrm{Ga}_{0.5} \mathrm{~N}$. The open symbols are experimental data from Ref. 38

substitutional Ga into AlN lattice.

$$
\left(\tau_{A}^{s}\right)^{-1}=\left(\frac{k_{B}}{\hbar}\right)^{4} \frac{V \Gamma_{A} y^{4} T^{4}}{4 \pi v^{3}}
$$

where

$$
\Gamma_{A}(x)=\sum_{i} c_{i}\left[\left[\frac{\triangle M_{i}}{M(x)}\right]^{2}+8 \gamma_{s}(x)^{2}(1-2 Q)^{2}\left[\frac{\triangle R_{i}}{R(x)}\right]^{2}\right]
$$

Here, the index $i$ denotes atomic constituents $(\mathrm{Ga}, \mathrm{Al}), c_{i}$ is the atomic fractional compositions, $\triangle M_{i}=M_{i}-M(x)$, $\triangle R_{i}=R_{i}-R(x), M(x)=x M_{A l}+(1-x) M_{G a}$, and $R(x)=$ $x R_{A l}+(1-x) R_{G a} . M(x)$ and $R(x)$ are averaged atomic mass and atomic radius of $\mathrm{Al}_{x} \mathrm{Ga}_{1-x} \mathrm{~N}$ alloy. The second term in Eq. (3) combines the difference in the atomic radius and the difference in the stiffness constant of the nearest-neighbor bonds. ${ }^{27}$ $\gamma_{s}(x)$ are the mode Grüneisen parameters, which describes the anharmonicity of the crystal lattice. Assuming that the incorporation of $\mathrm{Al}(\mathrm{Ga})$ into $\mathrm{GaN}(\mathrm{AlN})$ does not change significantly the anharmonicity of nearest-neighbor bonds, the parameter $Q$ has a value of $4.2{ }^{33}$

The $B$-scattering rate is assumed to be independent of temperature and phonon frequency and can be expressed as $^{17,18,22,23}$

$$
\tau_{B}^{-1}=\frac{v_{s}}{a L},
$$

where $L$ is the layer thickness, and $a$ is a dimensionless parameter. The $a L$ can be considered as an effective phonon mean free path (MFP) along the direction of the heat transport, which is essentially determined by the size effect. A value of 2.38 for the $a$ parameter have been found by fitting $\mathrm{Eq},(4)$ with the solution of Bolzman transport equation for a thin layer ${ }^{17}$ and used to model the thickness dependence of the thermal conductivity in GaN. ${ }^{17,18}$ In our analysis, we treat $a$ as a fitting parameter.

In applying the modified Callaway's model for $\mathrm{Al}_{x} \mathrm{Ga}_{1-x} \mathrm{~N}$ alloys, all material parameters needed for calculation of the different scattering rates (lattice constants, elastic constants, Debye temperatures, Grüneisen parameters) are linearly interpolated between the values for the binary GaN and AlN compounds. Such approach is justified by the experimental findings of a linear composition dependence of the lattice constants ${ }^{34}$ and the sound velocities ${ }^{35}$ in $\mathrm{Al}_{x} \mathrm{Ga}_{1-x} \mathrm{~N}$. The Grüneisen parameters $\gamma_{s}$ for LA and TA phonons in GaN and AlN were extracted by fitting the temperature dependence of thermal conductivity data ${ }^{36,37}$ with the modified Callaway's model described above. A least-square fit to the $\mathrm{GaN}$ data in the temperature range of $180-310 \mathrm{~K}$ yields $\gamma_{L A}=0.64$ and $\gamma_{T A}=0.31$, while $\gamma_{L A}=0.75$ and $\gamma_{T A}=0.35$ are extracted from the fit to the AIN data in the temperature range of 250$480 \mathrm{~K}$.

Figure 1 (a) presents the room temperature thermal conductivity of $\mathrm{GaN}$ and $\mathrm{Al}_{x} \mathrm{Ga}_{1-x} \mathrm{~N}$ as a function of layer thickness for various ranges of $\mathrm{Al}$ content. Recent literature data for $\mathrm{GaN}$ are also included in for comparison. ${ }^{18,30}$. The experimental data are fitted by the modified Callaway's model using the $a$ as the only adjustable parameter. When fitting the $\mathrm{Al}_{x} \mathrm{Ga}_{1-x} \mathrm{~N}$ data, $\mathrm{Al}$ composition in the middle of the range 
indicated in the figure is used. Also, the dislocation densities are fixed to $\mathrm{D}_{S}=1 \times 10^{9} \mathrm{~cm}^{-2}$ and $\mathrm{D}_{E}=1 \times 10^{10} \mathrm{~cm}^{-2}$. Note that the effect of the dislocations on the thermal conductivity of layers studied here comes mainly from the edge dislocations because their density is larger than the screw dislocation density by one order of magnitude. We have done a fitting of $\mathrm{Al}_{x} \mathrm{Ga}_{1-x} \mathrm{~N}$ data with $\mathrm{D}_{E}=6 \times 10^{9} \mathrm{~cm}^{-2}$ and $\mathrm{D}_{E}=3 \times 10^{10}$ $\mathrm{cm}^{-2}$ and have found that the the difference in the thermal conductivity is less than $10 \%$. Having in mind that the accuracy of our TTR measurements is $6-8 \%$, the using of the average edge dislocations in the fitting is justified. The best fit of the experimental data was obtained with $a=2.5$ for $\mathrm{GaN}$ and $a=1.5$ for $\mathrm{Al}_{x} \mathrm{Ga}_{1-x} \mathrm{~N}$ for all values of the $\mathrm{Al}$ content under investigation.

The results shown on Fig.1 (a) indicate a strong decrease of the thermal conductivity as the layer thickness becomes smaller than $1 \mu \mathrm{m}$, which is attributed to the effect of $B$ scattering. The slope of this decrease is less steeper for $\mathrm{Al}_{x} \mathrm{Ga}_{1-x} \mathrm{~N}$ than for GaN. Furthermore, the thermal conductivity for different $\mathrm{Al}$ contents has similar thickness dependence. Consequently, the experimental results for layers with close $\mathrm{Al}$ content fall on the same curve. For thicknesses greater than $5 \mu \mathrm{m}$, the thermal conductivity tends to saturate for both $\mathrm{GaN}$ and $\mathrm{Al}_{x} \mathrm{Ga}_{1-x} \mathrm{~N}$ layers.

In order to gain an insight into the phonon transport in $\mathrm{Al}_{x} \mathrm{Ga}_{1-x} \mathrm{~N}$ alloys, we calculated the cumulative thermal conductivity of thin $(1 \mu \mathrm{m})$ and thick $(1 \mathrm{~mm}) \mathrm{Al}_{0.5} \mathrm{Ga}_{0.5} \mathrm{~N}$ layers and compare it with that of GaN and AlN (Fig.1 (b)). The calculations were performed separately for LA and TA phonons using the modified Callaway's model. The cumulative thermal conductivity were obtained by summation of the contributions from all phonon branches. For thick $\mathrm{GaN}$ and AlN layers, the phonon mean-free-path (MFP) at $50 \%$ of the thermal conductivity contribution is $\mathrm{MFP}_{50}=900 \mathrm{~nm}$ and $\mathrm{MFP}_{50}=670 \mathrm{~nm}$, respectively. These values are very close to the experimental data reported by Freedman et al. ${ }^{38}$ For $\mathrm{Al}_{0.5} \mathrm{Ga}_{0.5} \mathrm{~N}$, we obtain significantly larger value of $\mathrm{MFP}_{50}$ $=29 \mu \mathrm{m}$. This can be explained by a strong $A$-scattering of high-frequency phonons corresponding to a short MFP. Hence, the thermal conductivity contribution mostly stems from the low-frequency phonons (with long MFP) and the $\mathrm{MFP}_{50}$ of $\mathrm{Al}_{0.5} \mathrm{Ga}_{0.5} \mathrm{~N}$ is expected to be longer than those of $\mathrm{GaN}$ and AlN. Indeed, it is longer by about 1 order of magnitude. A similar behaviour has been reported for $\operatorname{In}_{x} \mathrm{Ga}_{1-x} \mathrm{~N}$ alloys $^{39,40}$.

In the case of $1-\mu \mathrm{m}$-thick layers, we obtained $\mathrm{MFP}_{50}=$ $310 \mathrm{~nm}$ for $\mathrm{GaN}, \mathrm{MFP}_{50}=360 \mathrm{~nm}$ for $\mathrm{AlN}$, and $\mathrm{MFP}_{50}=$ $260 \mathrm{~nm}$ for $\mathrm{Al}_{0.5} \mathrm{Ga}_{0.5} \mathrm{~N}$. These values are approximately 3 times smaller compared to that of $1-\mathrm{mm}$-thick GaN and AlN layers. The large difference in the $\mathrm{MFP}_{50}$ of thin and thick $\mathrm{Al}_{0.5} \mathrm{Ga}_{0.5} \mathrm{~N}$ layers indicates that the long-MFP phonons, which mainly contribute to the thermal conductivity, are efficiently scattered at the boundaries resulting in a reduction of the thermal conductivity.

Figure 2 shows the experimentally determined room temperature thermal conductivity of the $\mathrm{Al}_{x} \mathrm{Ga}_{1-x} \mathrm{~N}$ layers as a function of $\mathrm{Al}$ content, where only data for layer thickness larger than $1 \mu \mathrm{m}$ is plotted. This is justified considering

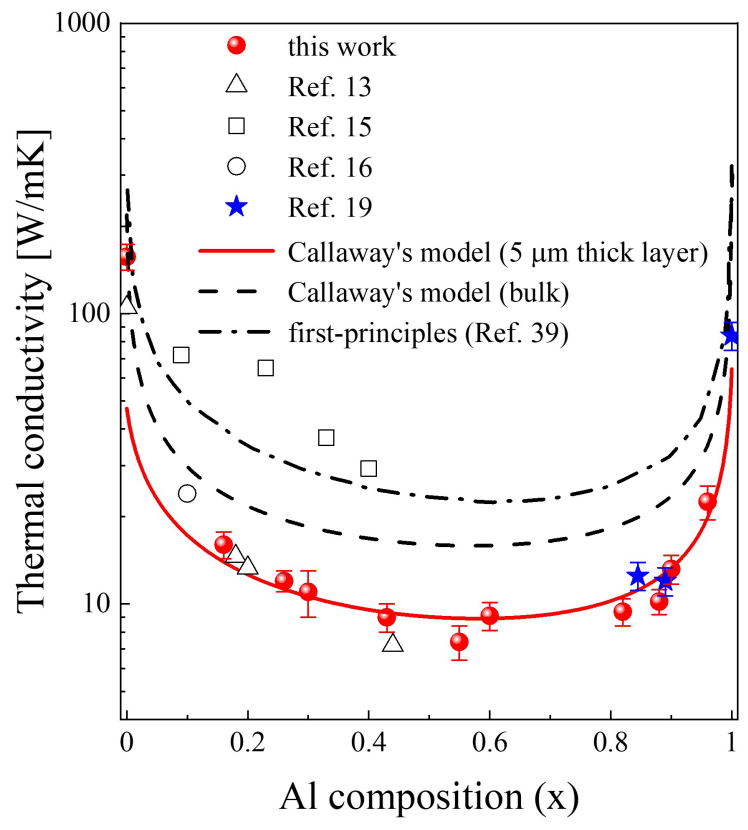

FIG. 2. Thermal conductivity of $\mathrm{Al}_{x} \mathrm{Ga}_{1-x} \mathrm{~N}$ at room temperature as a function of $\mathrm{Al}$ composition. Experimental data (symbols) and the theoretical calculations (curves) at room temperature are shown.

that the thermal conductivity tends to saturate at several micrometers. In addition, the calculated composition dependence of the thermal conductivity of a $5 \mu \mathrm{m}$ thick $\mathrm{Al}_{x} \mathrm{Ga}_{1-x} \mathrm{~N}$ layer with dislocation densities $\mathrm{D}_{S}=1 \times 10^{9} \mathrm{~cm}^{-2}$ and $\mathrm{D}_{E}=$ $1 \times 10^{10} \mathrm{~cm}^{-2}$ is also shown. Using our treatment of the $A$ scattering strength (Eq. (3)) a very good agreement between the calculated and the experimental results is achieved. The proper treatment of the lattice distortion due to the atomic mass, atomic radius and bond stiffness constants fluctuations leads to an asymmetry in the composition dependence of the thermal conductivity as seen in Fig. 2. By separating the contributions of the two terms in Eq. (3), we found that they equally contribute to the thermal conductivity degradation in the $\mathrm{Al}_{x} \mathrm{Ga}_{1-x} \mathrm{~N}$ alloys, however, only the mass fluctuation accounts for the asymmetry effect. The minimum of the thermal conductivity of $\mathrm{Al}_{x} \mathrm{Ga}_{1-x} \mathrm{~N}$ is found to occur around $\mathrm{x}=0.6$.

In Fig. 2, are also shown published experimental data for thermal conductivity of $\mathrm{Al}_{x} \mathrm{Ga}_{1-x} \mathrm{~N}$ epitaxial layers. ${ }^{13,15,16,19}$ A good agreement between our results and the thermal conductivity measured by TTR or time-domain termoreflectance (TDTR) in Refs. 13, 16 and 19 is observed. On the other hand, the thermal conductivity measured by $3 \omega$ method in Ref. [15] are somewhat larger, which may be attributed to the different experimental techniques used.

Using the modified Callaway's model, we have calculated the thermal conductivity of bulk dislocation-free $\mathrm{Al}_{x} \mathrm{Ga}_{1-x} \mathrm{~N}$ and compared with the first-principles calculations ${ }^{39}$ (Fig. 2). The apparent difference is attributed to the fact that in the treatment of the $A$-scattering in Ref. [39] only the mass fluctuation is taken into account.

In summary, we have studied the interplay between 
phonon-alloy and phonon-boundary scattering in the thermal conductivity of $\mathrm{Al}_{x} \mathrm{Ga}_{1-x} \mathrm{~N}$ layers with $0 \leq x \leq 0.96$ and various thicknesses. In comparison with $\mathrm{GaN}$, the phononboundary scattering is found to play a different role in $\mathrm{Al}_{x} \mathrm{Ga}_{1-x} \mathrm{~N}$ alloys, where the thermal conductivity is strongly suppressed due to the phonon-alloy scattering. The thickness dependence of the thermal conductivity of $\mathrm{Al}_{x} \mathrm{Ga}_{1-x} \mathrm{~N}$ is weaker compared to $\mathrm{GaN}$ and nearly independent of the $\mathrm{Al}$ composition. We have shown that in $\mathrm{Al}_{x} \mathrm{Ga}_{1-x} \mathrm{~N}$ the thermal conductivity is governed by phonons with a much longer MFP than that in the binary compounds. Hence, for thin layers (with thickness less than MFP) the phonon-boundary scattering will play a significant role reducing the thermal conductivity. These findings have important implications for the design and thermal management of $\mathrm{Al}_{x} \mathrm{Ga}_{1-x} \mathrm{~N}$-containing electronic devices. We have also highlighted the experimentally observed asymmetry in the thermal conductivity dependence on $\mathrm{Al}$ composition, which is attributed to a fluctuation of the mass of metal atoms in the alloy.

\section{ACKNOWLEDGMENTS}

The authors are indebted to Dr. J. H. Leach from Kyma Technologies, Inc. for providing the HVPE samples for this study. This work is performed within the competence centers for III-Nitride Technology (C3NiT-Janzén) supported by the Swedish Governmental Agency for innovation systems (VINOVA) under the Competence Center Program Grant No. 2016-05190. We further acknowledge support from the Swedish Research Council VR under Grands No. 2016-00889 and 2017-03714, Swedish Foundation for Strategic Research under Grants No. No. RIF14-055 and No. EM16-0024, and the Swedish Government Strategic Research Area in Materials Science on Functional Materials at Linköping University, Faculty Grant SFO Mat LiU No. CBET-1336464 and DMR1506159. The work at NCSU was supported by NSF Grants No. CBET-1336464 and DMR-1506159.

\section{DATA AVAILABILITY}

The data that support the findings of this study are available within the article.

${ }^{1}$ J. Y. Tsao, S. Chowdhury, M. A. Hollis, D. Jena, N. M. Johnson, K. A. Jones, R. J. Kaplar, S. Rajan, C. G. V. de Walle, E. Bellotti, C. L. Chua, R. Collazo, M. E. Coltrin, J. A. Cooper, K. R. Evans, S. Graham, T. A. Grotjohn, E. R. Heller, M. Higashiwaki, M. S. Islam, P. W. Juodawlkis, M. A. Khan, A. D. Koeher, J. H. Leach, U. K. Mishra, R. J. Nemanich, R. C. N. Pilawa-Podgurski, J. B. Shealy, Z. Sitar, M. J. Tadjer, A. F. Witulski, M. Wraback, and J. A. Simmons, Adv. Electron. Mater. 4, 1600501 (2018).

${ }^{2}$ J. L. Hudgings, G. S. Simin, E. Santi, and M. A. Khan, IEEE Trans. Power Electron. 18, 907 (2003).

${ }^{3}$ Y. Taniyasu, M. Kasu, and N. Kobayashi, "Intentional control of $n$-type conduction for si-doped aln and $\mathrm{al}_{x} \mathrm{ga}_{1-x} \mathrm{n}(0.42<\mathrm{x}<1)$," Appl. Phys. Lett. 81, 1255 (2002).

${ }^{4}$ F. Mehnke, T. Wernicke, H. Pingel, C. Kuhn, C. Reich, V. Kueller, A. Knauer, M. Lapeyrade, M. Weyers, and M. Kneissl, Appl. Phys. Lett. 103, 212109 (2013).
${ }^{5}$ T. Kinoshita, T. Obata, H. Yanagi, and S. Inoue, Appl. Phys. Lett. 102, 012105 (2013).

${ }^{6} \mathrm{~S}$. Schöche, T. Hofmann, D. Nilsson, A. Kakanakova-Georgieva, E. Janzén, P. Kühne, K. Lorenz, M. Schubert, and V. Darakchieva, J. Appl. Phys. 121, 205701 (2017).

${ }^{7}$ T. Nanjo, M. Takeuchi, Suita, T. Oishi, Y. Abe, Y. Tokuda, and Y. Aoyagi, Appl. Phys. Lett. 92, 263502 (2008).

${ }^{8}$ H. Tokuda, M. Hatano, N. Yafune, S. Hashimoto, K. Akita, Y. Yamamoto, and M. Kuzuhara, Appl. Phys. Express 3, 121003 (2010).

${ }^{9}$ T. Nanjo, A. Imai, Y. Suzuki, Y. Abe, T. Oishi, M. Suita, E. Yagyu, and Y. Tokuda, IEEE Trans Electron Devices 60, 1046 (2013).

${ }^{10}$ Y. Wu, J. Zhang, S. Zhao, W. Zhang, Y. Zhang, X. Duan, J. Chen, and Y. Hao, IEEE Electron Device Lett. 40, 1724 (2019).

${ }^{11}$ A. A. Allerman, A. M. Amstrong, A. J. Fischer, J. R. Dickerson, M. H. Crawford, M. P. King, M. W. Moseley, J. J. Wierer, and R. J. Kaplar, Electron. Lett. 52, 1319 (2016).

${ }^{12}$ R. Dalmau, H. S. Craft, R. Schlesser, S. Mita, J. Smart, G. P. C. Hitchcock, T. P. Chow, and B. Moody, ECS Trans. 80, 217 (2017).

${ }^{13}$ B. C. Daly, H. J. Maris, A. V. Nurmikko, M. Kuball, and J. Han, J. Appl. Phys. 92, 3820 (2002).

${ }^{14}$ W. Liu and A. A. Balandin, Appl. Phys. Lett. 85, 5230 (2004).

${ }^{15}$ W. Liu and A. A. Balandin, J. Appl. Phys. 97, 073710 (2005).

${ }^{16}$ Y. R. Koh, M. A. Shirazi-HD, B. Vermeersch, A. M. S. Mohammed, J. Shao, G. Pernot, J. H. Bahk, M. J. Manfra, and A. Shakouri, Appl. Phys. Lett. 109, 243107 (2016).

${ }^{17}$ T. E. Beechem, A. E. McDonald, E. J. Fuller, A. A. Talin, C. M. Rost, J. P. Maria, J. T. Gaskins, P. E. Hopkins, and A. A. Allerman, J. Appl. Phys. 120, 095104 (2016).

${ }^{18}$ E. Ziade, J. Yang, G. Brummer, D. Nothern, T. Moustakas, and A. J. Schmidt, Appl. Phys. Lett. 110, 031903 (2017).

${ }^{19}$ D. Q. Tran, N. Blumenschein, A. Mock, P. Sukkaew, H. Zhang, J. F. Muth, T. Paskova, P. P. Paskov, and V. Darakchieva, Physica B Condens. Matter $\mathbf{5 7 9}, 411810$ (2020)

${ }^{20}$ J. Callaway, Phys. Rev. 113, 1046 (1959).

${ }^{21}$ M. G. Holland, Phys. Rev. 132, 2461 (1963).

${ }^{22}$ M. Asen-Palmer, K. Bartkowski, E. Gmelin, M. Cardona, A. P. Zhernov, A. V. Inyushkin, A. Taldenkov, V. I. Ozhogin, K. M. Itoh, and E. E. Haller, Phys. Rev. B 56, 9431 (1997).

${ }^{23}$ D. T. Morelli, J. P. Heremans, and G. A. Slack, Phys. Rev. B 66, 195304 (2002).

${ }^{24}$ D. S. Tang, G. Z. Qin, M. Hu, and B. Y. Cao, J. Appl. Phys. 127, 035102 (2020).

${ }^{25}$ J. Garg, T. Liu, and G. Chen, Appl. Phys. Lett. 112, 252101 (2018).

${ }^{26}$ J. Zou, D. Kotchetkov, A. A. Balandin, D. I. Florescu, and F. H. Pollak, J. Appl. Phys. 92, 2534 (2002).

${ }^{27}$ P. P. Paskov, M. Slomski, J. H. Leach, J. F. Muth, and T. Paskova, AIP Advances 7, 095302 (2017).

${ }^{28}$ C. Mion, J. F. Muth, E. A. Preble, and D. Hanser, Appl. Phys. Lett. 89, 092123 (2006).

${ }^{29}$ K. Park and C. Bayram, J. Appl. Phys. 126, 185103 (2019).

${ }^{30}$ R. D. Carrascon, D. Q. Tran, P. Sukkaew, A. Mock, R. Ciechonski, J. Ohlsson, Y. Zhu, O. Hultin, B. Monemar, P. P. Paskov, L. Samuelson, and V. Darakchieva, Phys. Status Solidi B 257, 1900581 (2020).

${ }^{31}$ B. Abeles, Phys. Rev. 131, 1906 (1963).

${ }^{32}$ S. Adachi, J. Appl. Phys. 54, 1844 (1983).

${ }^{33}$ P. G. Klemens, Proc. Phys. Soc. A 68, 1113 (1955).

${ }^{34}$ H. Angerer, D. Brunner, F. Freudenberg, O. Ambacher, M. Stutzmann, R. Höopler, T. Metzger, E. Born, G. Dollinger, A. Bergmaier, S. Karsch, and H. J. Körner, Appl. Phys. Lett. 71, 1504 (1997).

${ }^{35}$ J. Rubio-Zuazo, R. J. Jimenez-Rioboo, E. Rodriguez-Canas, C. Prieto, T. Palacios, F. Calle, E. Monroy, and M. A. Sanchez-Garcia, Mater. Sci. Eng. B 93, 168 (2002).

${ }^{36}$ G. A. Slack, L. J. Schowalter, D. Morelli, and J. A. F. Jr., J. Cryst. Growth 246, 287 (2002).

${ }^{37}$ Z. Cheng, Y. R. Koh, A. Mamun, J. Shi, T. Bai, K. Huynh, L. Yates, Z. Liu, R. Li, E. Lee, M. E. Liao, Y. Wang, H. M. Yu, M. Kushimoto, T. Luo, M. S. Goorsky, P. E. Hopkins, H. Amano, A. Khan, and S. Graham, Phys. Rev. Mater. 4, 044602 (2020).

${ }^{38}$ J. P. Freedman, J. H. Leach, E. A. Preble, Z. Sitar, R. F. Davis, and J. A. Malen, Sci Rep 3, 2963 (2013). 
${ }^{39}$ J. Ma, W. Li, and X. Luo, J. Appl. Phys. 119, 125702 (2016).

${ }^{40}$ D. Xu, Q. Wang, X. Wu, J. Zhu, H. Zhao, B. Xiao, X. Wang, X. Wang, and Q. Hao, Front. Energy 12, 127 (2018) 